\title{
The association of thyroid-stimulating hormone (TSH) and free thyroxine (fT4) concentration levels with carbohydrate and lipid metabolism in obese and overweight teenagers
}

\author{
Katarzyna A. Korzeniowska', Michał Brzeziński, ${ }^{3}$, Kamila Szarejko', Marcin Radziwiłł', \\ Tomasz Anyszek ${ }^{2,4}$, Leszek Czupryniak2, 5, Piotr Soszyński², ${ }^{2}$, Per-Olof Berggren7, Małgorzata Myśliwiec ${ }^{1,2}$ \\ ${ }^{1}$ Department of Paediatrics, Diabetology, and Endocrinology, Medical University of Gdansk, Gdansk, Poland \\ 2"PoZdro" Scientific Board, Medicover Foundation, Warsaw, Poland \\ ${ }^{3}$ Department of Public Health and Social Medicine, Medical University of Gdansk, Gdansk, Poland \\ ${ }^{4}$ Synevo Polska, Warsaw, Poland \\ ${ }^{5}$ Department of Internal Diseases and Diabetology, Warsaw Medical University, Warsaw, Warsaw, Poland \\ ${ }^{6}$ Medicover Sp. z.o.o., Warsaw, Poland \\ ${ }^{7}$ Department of Molecular Medicine and Surgery, Karolinska Insitutet, Stockholm, Sweden
}

\begin{abstract}
Introduction: Obesity has increased rapidly among children and adolescents during the last 30 years. Paediatric patients with a BMI above the $85^{\text {th }}$ centile are more often diagnosed with increased TSH levels than are children with proper body weight.

Material and methods: The data of 961 overweight and obese children, aged 13 years, recruited in four cities in Poland as part of PoZdro!, a two-year prophylactic program, were analysed to observe the relationship between serum TSH and fT4 concentration and carbohydrate and lipid metabolism parameters, as well as anthropometric parameters.

Results: TSH concentration in the study group was positively correlated, whereas fT4 concentration was negatively correlated with WHR and WHtR values, fasting serum glucose concentrations and one-hour glucose concentration, fasting serum insulin concentrations, one-hour and two-hour insulin concentration, ALT serum activity, as well as total cholesterol, LDL cholesterol, and triglyceride serum concentrations. An increased risk of metabolic syndrome was diagnosed previously in patients with TSH concentrations $>2.5 \mathrm{mUI} / \mathrm{L}$. Conclusions: TSH concentration in the upper half of the current reference range $(>2.50 \mathrm{mIU} / \mathrm{L})$ is associated with an increased risk of lipid and carbohydrate metabolism disorders and therefore increased chances of developing metabolic syndrome. It seems advisable to regularly monitor thyroid function in overweight and obese paediatric patients. (Endokrynol Pol 2019; 70 (2): 172-178)
\end{abstract}

Key words: thyroid; overweight; children; lipids; obesity; glucose metabolism

\section{Introduction}

During the last 30 years a significant increase in obesity among children has been observed [1,2]. The incidence rate of excessive body mass in children and teenagers in Poland is $3.4-17.2 \%$, which is comparable to other developed countries in the world [3-5]. However, the connection between thyroid activity in children and the development of metabolic syndrome, insulin resistance, or lipid metabolism disorders has not yet been fully explained [6-8].

Serum thyroid-stimulating hormone (TSH) and free thyroxine (ft4) concentrations in children with excessive body mass are constantly fluctuating [9]; therefore, it is not entirely clear whether the wide range of TSH reference values (uniform for the entire population) should be modified. Thyroid hormones are primarily respon- sible for maintaining the body's energy homeostasis, as well as regulating lipid and carbohydrate metabolism [10]. A reduced free thyroxine (fT4) concentration seems to be connected with insulin resistance increase and metabolic syndrome development, which contributes to an increase of cardiovascular risk [11, 12].

The study attempted to identify the association of serum TSH and fT4 concentrations with carbohydrate and lipid metabolism parameters.

\section{Material and methods}

The analysis incorporated data for 961 children, including 442 $(46.0 \%)$ girls and $519(54 \%)$ boys, overweight or obese, aged 13 years, recruited from four cities in Poland (Gdynia, Warsaw, Lublin, and Wrocław) in the years 2013-2016 as part of the PoZdro! National Program for the Prevention of Diabetes and Civilisation-related Diseases (Ogólnopolski Program Profilaktyki Cukrzycy i Chorób Cywilizacyjnych PoZdro!). 
During visits the patients had their anthropometric parameters measured: height, body mass, waist and hip circumference, and triplicate measurements of arterial blood pressure.

Height was measured using a stadiometer under standard conditions, with patients in the Frankfurt position, without shoes. Body mass was measured using an electronic scale with bioimpendance, with patients in their underwear and without shoes. The children's waist and hip circumference measurements were conducted using anthropometric tape, with patients in a standing position. Waist circumference measurements were taken at the mid-distance between the costal arches and iliac wings, while hip circumference measurements were taken at the widest point below the iliac wings. BMI was calculated based on the above measurements. Being obese or overweight was defined based on age- and gender-specific BMI centile grids, developed as part of the OLAF project [13, 14]. Overweight was defined as ranging from the $85^{\text {th }}$ to the $95^{\text {th }}$ centile, whereas obesity as being at or above the $95^{\text {th }}$ centile for the specific gender and age group [13]

The following laboratory tests were also conducted for all patients: peripheral blood cell count, TSH and fT4 concentration, oral glucose tolerance test with assessment of glucose and insulin levels (fasting, one-hour and two-hour), ALT activity, lipid panel (total cholesterol, LDL cholesterol, HDL cholesterol, triglycerides), uric acid, and creatinine. Whole blood samples collected from the patients were used for the complete blood count, while serum was used for other tests. Blood samples were collected after a minimum of eight hours of fasting.

As the normal range for all measurements we used the cut-offs for 13-year-olds used by Synevo Laboratories, where all the measurements were performed. The normal range of TSH used for 13 years old was $0.27-4.2 \mu \mathrm{IU} / \mathrm{mL}$ and for fT4 levels $12-22 \mathrm{pmol} / \mathrm{l}$. Patients with TSH level above $10 \mathrm{mU} / \mathrm{l}$ and fT4 levels below normal range were diagnosed with hypothyroiditis and started the treatment with L-thyroxine.

Metabolic syndrome was diagnosed based on IDF (International Diabetes Federation) criteria from 2007. (14) Children with waist circumference above $90^{\text {th }}$ percentile and two or more accompanying laboratory founds (triglycerides $>150 \mathrm{mg} / \mathrm{dL} ; \mathrm{HDL}<40 \mathrm{mg} / \mathrm{dL}$; glucose level $>100 \mathrm{mg} / \mathrm{dL}$; blood pressure $>130 / 85 \mathrm{~mm} \mathrm{Hg}$ ) were diagnosed with metabolic syndrome.

All calculations were conducted using the Statistica 10 software (StatSoft, United States of America), with the assumed statistical significance threshold of $p \leq 0.05$.

Normality of distribution for the analysed quantitative variables was assessed using the Shapiro-Wilk test. Statistical characteristics of quantitative variables were presented as arithmetic means, stan- dard deviations (SD), medians, and extreme values (minimum and maximum). Statistical characteristics of qualitative variables were presented as numeric and percentage distributions. The MannWhitney U test or the Kruskal-Wallis test with post-hoc Dunn's test were used for inter-group comparisons of statistical characteristics of the measurable variables. In order to compare inter-group distributions of qualitative variables, Pearson's chi-squared test was used. The power and direction of the correlation between pairs of measurable variables was assessed on the basis of Spearman's rank correlation coefficient values $(R)$.

All parents of the pupils taking part in the PoZdro! Program signed informed consent forms. The Ethics Committee from Medical University of Gdansk agreed to the investigation (NKBBN/301/2014). The reported investigations were carried out in accordance with the principles of the Declaration of Helsinki as revised in 2000

\section{Results}

Statistical characteristics of the TSH and fT4 concentrations for the entire study group are presented in Table I.

Study subjects included $472(49.1 \%)$ overweight children and 489 (50.9\%) obese children. There was no significant difference between the groups in terms of TSH concentration. However, fT4 concentration in overweight children was significantly higher than in the obese ones (Tab. II). In the entire group there were three adolescents with TSH level above $10 \mu \mathrm{IU} / \mathrm{mL}$ (11.7 $\mu \mathrm{IU} / \mathrm{mL}, 13.8 \mu \mathrm{IU} / \mathrm{mL}$, and $14 \mu \mathrm{IU} / \mathrm{mL}$, respectively), who were diagnosed with hypothyroidism and started L-thyroxine treatment. The data of those three patients were not excluded from the study; however, further analyses revealed no statistical differences whether these data were or were not taken into consideration.

Values of lipid profile were as following (mean and standard deviation) - total cholesterol $155 \pm 28 \mathrm{mg} \%$; LDL-cholesterol $92 \pm 49 \mathrm{mg} \%$; triglycerides $86 \pm 24 \mathrm{mg} \%$ and HDL-cholesterol $50 \pm 11 \mathrm{mg} \%$.

Table I. Statistical characteristics of the thyroid-stimulating hormone (TSH) and free thyroxine (fT4) concentrations for the entire study group

\begin{tabular}{lcccccc}
\hline Variable & $\mathbf{n}$ & Mean & Median & Minimum & Maximum & SD \\
\hline TSH $[\mathrm{mU} / \mathrm{L}]$ & 961 & 2.49 & 2.24 & 0.47 & 14.03 & 1.32 \\
\hline fT4 $[\mathrm{pmol} / \mathrm{L}]$ & 961 & 15.13 & 15.05 & 8.52 & 44.18 & 2.36 \\
\hline
\end{tabular}

SD — standard deviation

Table II. Comparison of thyroid-stimulating hormone (TSH) and free thyroxine (fT4) concentration levels in overweight and obese children

\begin{tabular}{lcccccc}
\hline \multirow{2}{*}{ Variable } & \multicolumn{3}{c}{ Overweight $(\mathbf{n}=\mathbf{4 7 2})$} & \multicolumn{3}{c}{ Obesity $(\mathbf{n}=\mathbf{4 8 9})$} \\
\cline { 2 - 7 } & Mean & Median & SD & Mean & Median & SD \\
\hline TSH $[\mathrm{mU} / \mathrm{L}]$ & 2.43 & 2.19 & 1.25 & 2.54 & 2.27 & 1.40 \\
\hline fT4 $[\mathrm{pmol} / \mathrm{L}]$ & 15.34 & 15.29 & 2.9 & 14.92 & 14.82 & 2.21 \\
\hline
\end{tabular}

SD — standard deviation 


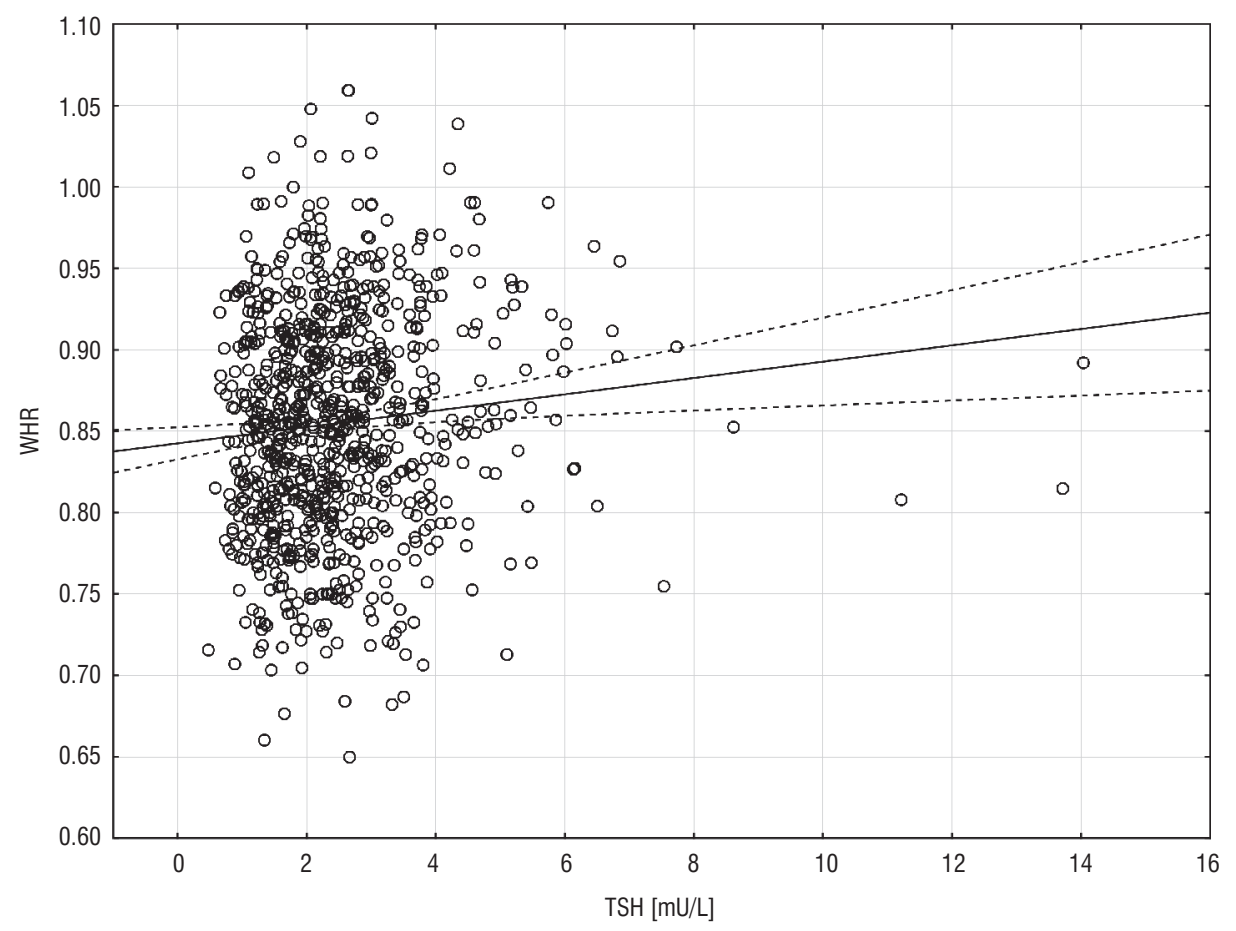

Figure 1. Waist-to-hip ratio (WHR) according to thyroid-stimulating hormone (TSH) concentration

The analysis of anthropometric parameters revealed positive correlations between TSH concentration and both WHR $(\mathrm{R}=0.114, \mathrm{p}<0.005)$ and WHtR $(\mathrm{R}=0.095$, $p=0.003$ ) values for the entire study group (Fig. 1).

The interpretation of the carbohydrate metabolism results revealed a positive correlation between TSH concentration and fasting glucose concentration ( $R=0.091, p=0.005)$ and one-hour glucose concentration $(\mathrm{R}=0.151, \mathrm{p}<0.005)$, fasting insulin concentration ( $R=0.172, p<0.005)$, one-hour insulin concentration $(\mathrm{R}=0.193, \mathrm{p}<0.005)$ and two-hour insulin concentration ( $R=0.145, p<0.005)$ (Fig. 2). There was, however, a negative correlation between $\mathrm{fT} 4$ concentration and fasting glucose concentration $(R=-0.109, p=0.001)$ and two-hour glucose concentration $(R=-0.079$, $\mathrm{p}=0.015)$, fasting insulin concentration $(\mathrm{R}=-0.259$, $\mathrm{p}<0.005)$, one-hour insulin concentration $(\mathrm{R}=-0.122$, $\mathrm{p}<0.005)$ and two-hour insulin concentration $(\mathrm{R}=-0.114, \mathrm{p}=0.001)$.

In the lipid profile analysis a positive correlation was noted between TSH concentration and total cholesterol $(\mathrm{R}=0.142, \mathrm{p}<0.005)$, LDL cholesterol $(\mathrm{R}=0.251$, $\mathrm{p}<0.005)$, and triglycerides $(\mathrm{R}=0.107, \mathrm{p}=0.001)$, and a negative correlation between fT4 concentrations and those of total cholesterol $(\mathrm{R}=-0.085, \mathrm{p}=0.008)$ and LDL-cholesterol $(\mathrm{R}=-0.167, \mathrm{p}<0.005)$.

At the next stage the patients were divided into three groups based on their TSH concentrations: $<2.50 \mathrm{mU} / \mathrm{L}$ $(\mathrm{n}=579) ; 2.50-4.50 \mathrm{mU} / \mathrm{L}(\mathrm{n}=319) ;>4.50 \mathrm{mU} / \mathrm{L}$ $(\mathrm{n}=63)$.
Teenagers with TSH concentrations $<2.50 \mathrm{mU} / \mathrm{L}$ $(\mathrm{n}=579)$ exhibited statistically significantly lower WHR ( $p=0.03)$, WHtR ( $p=0.007)$, lower fasting glucose concentration $(p=0.008)$ and one-hour glucose concentration $(p=0.001)$, lower fasting insulin concentration ( $p=0.001$ ) and one-hour insulin concentration $(\mathrm{p}<0.005)$ and two-hour insulin concentration $(p=0.005)$, as well as lower concentrations of total cholesterol ( $p=0.001)$, LDL cholesterol $(p<0.005)$, and triglycerides $(\mathrm{p}=0.021)$ than the other two groups (Fig. 3, 4).

Metabolic syndrome was diagnosed in $70(7.5 \%)$ patients, $582(60 \%)$ teenagers had BMI between 25 and 30 years old, and $119(12.4 \%)$ patients had BMI $>30$.

Thirty-one (3.2\%) patients from the entire group had elevated fasting blood glucose level; however, none was diagnosed with diabetes mellitus. Eleven $(1.17 \%)$ patients had triglycerides $>150 \mathrm{mg} / \mathrm{dL}$, and $184(19.1 \%)$ teenagers had HDL-cholesterol level < 40 mg/dL. 252 (26.2\%) patients had blood pressure above $130 / 85 \mathrm{~mm} \mathrm{Hg}$.

\section{Discussion}

Numerous scientific reports identify a correlation between obesity and increased occurrence of overt or sub-clinical hypothyroidism [15]. It is commonly known that excessive adipose tissue may contribute to disorders of the pituitary-thyroid axis functioning and, as a consequence, cause thyroid function disorders. Due to the multi-directional action of thyroid hormones, this 


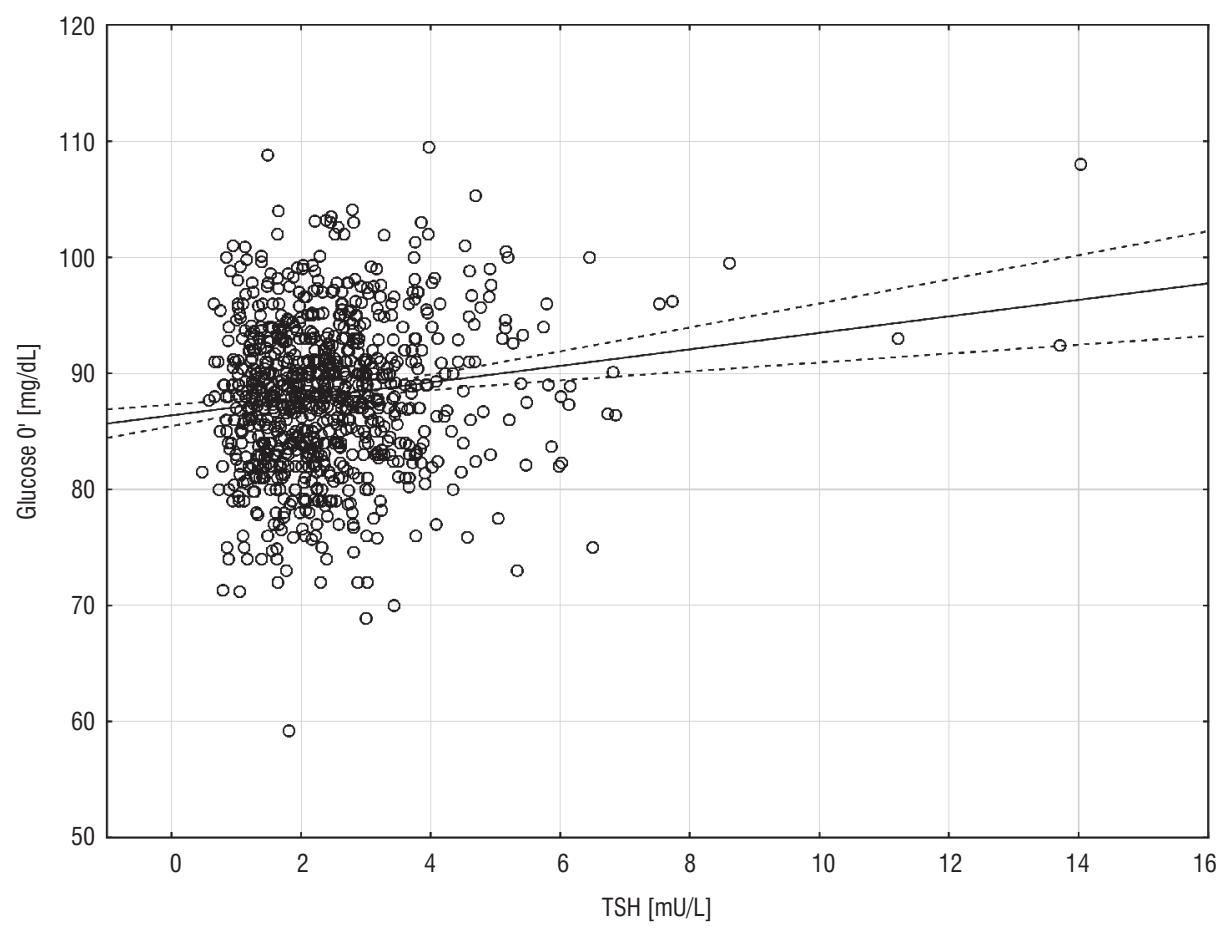

Figure 2. Glucose level according to thyroid-stimulating hormone (TSH) level

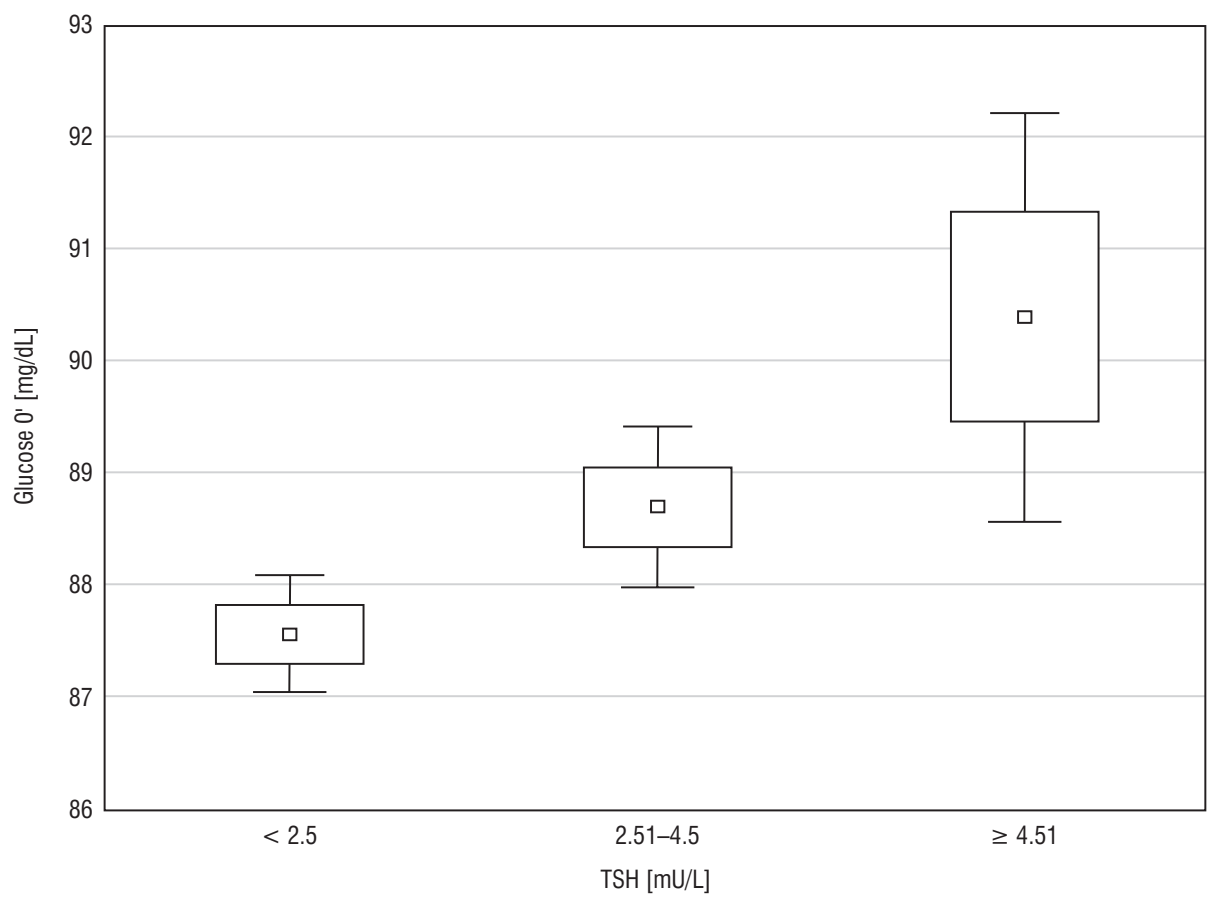

Figure 3. Glucose level at the baseline according to thyroid-stimulating hormone (TSH) levels

may exert an indirect negative impact on the functioning of multiple organs and systems [16].

Numerous publications have attempted to compare TSH concentrations between obese children and those with normal body mass, demonstrating a statistically significant increase in TSH concentrations in children with excessive body mass $[7,8]$. Some researchers have also demonstrated significantly higher free thyroxine (fT4) concentrations in obese children versus those with normal body mass. They attributed this fact to a higher conversion of thyroxine (fT4) to free triiodothyronine (fT3) caused by increased deiodinase activity, as a compensation mechanism that increases energy consumption in cases of excess adipose tissue accumulation. 


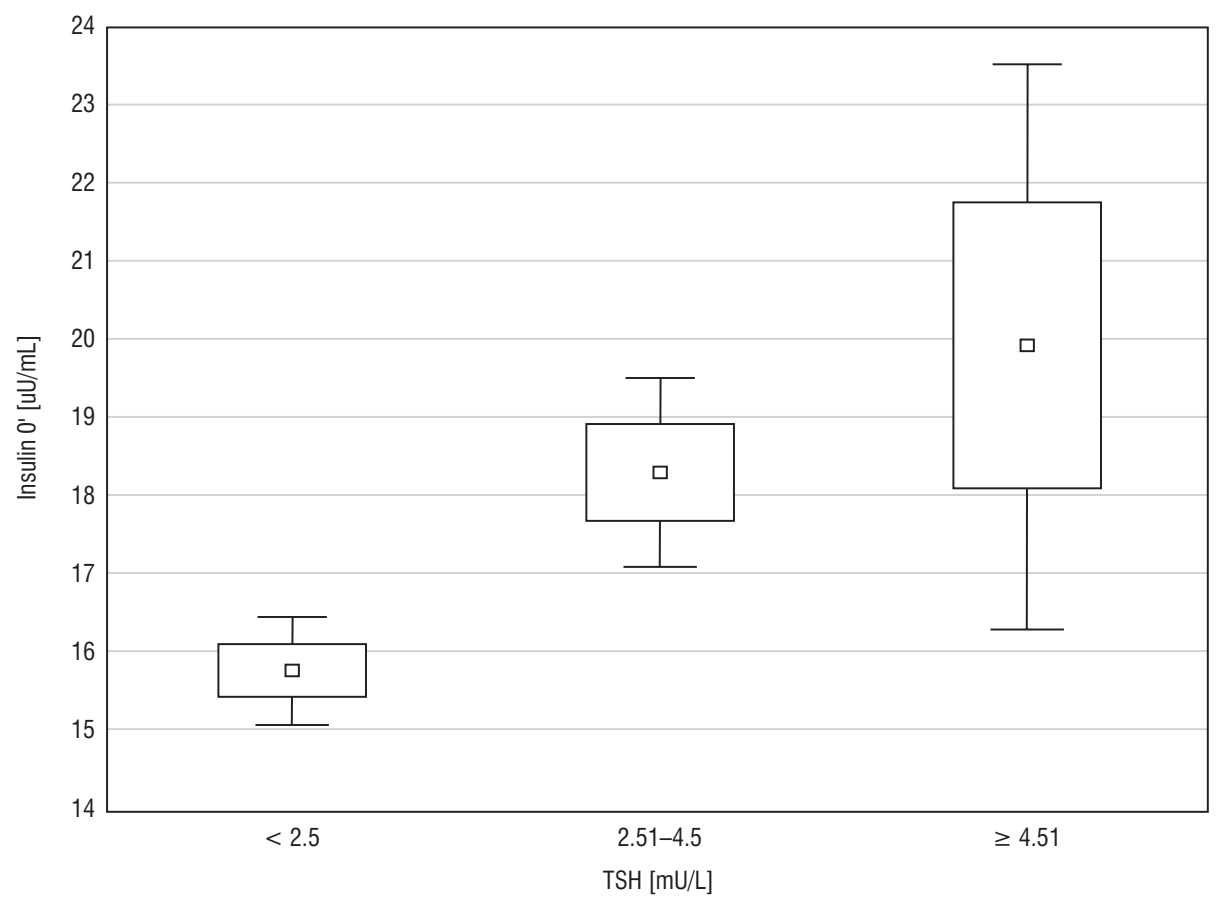

Figure 4. Insulin levels according to thyroid-stimulating hormone (TSH) levels

However, these hypotheses were not supported by other studies $[9,10]$.

Our study reported no differences in TSH concentrations between overweight and obese children. However, statistically significant lower free thyroxine concentrations were observed in obese children versus overweight children.

The next stage of the study was to demonstrate the association between TSH and fT4 concentrations, and anthropometric parameters (WHR, WHtR, BMI), glucose and insulin concentrations, and lipid profile.

Polish researchers have attempted a retrospective analysis of data acquired from 110 obese children, which were compared against test results from 38 healthy non-obese children aged 5 to 18 years. A positive correlation between TSH concentration and both BMI and WHR was identified [4].

Tiller et al. demonstrated a strong positive correlation between TSH concentration and waist circumference, and WHR [17], on a large group of the German population, which is in line with our observations.

Interesting data is provided by analysing a paper by Turkish researchers, who demonstrated on a group of 111 obese teenagers and 42 healthy peers that the obese patients had higher TSH concentrations, which positively correlated with total cholesterol, LDL cholesterol, triglycerides, and fasting insulin concentrations [18]. Similar conclusions were drawn by Norwegian researchers, who, having examined the medical records of 30,000 patients without a coexisting thyroid disease, demonstrated that along with an increase in TSH concentration (still within the generally accepted reference range for the population) there were statistically significant increases in total cholesterol concentration, LDL cholesterol, triglycerides, and a reduction in HDL cholesterol concentration [19].

On the other hand, Radetti et al. in their retrospective study on 833 adolescents showed that elevated TSH levels in obese teenagers could negatively influence the cardiac status of the patients because of higher total cholesterol level as well as higher blood pressure [20].

Therefore, most researchers agree that the higher the thyrotropin concentration, the more disrupted the carbohydrate metabolism is (higher fasting glucose and two-hour glucose concentrations), which is accompanied by an increase of cardiovascular risk due to increased concentrations of total cholesterol, LDL cholesterol, and triglycerides. The question therefore arises: what TSH concentration can be considered safe in terms of metabolic consequences and well-tolerated in paediatric patients? Should we modify the generally accepted interpretation of TSH reference values or define risk thresholds for the development of metabolic complications?

The next stage of our study was the division of patients according to TSH concentrations. In the subsequent tests it was noted that the teenagers from the group with the lowest TSH concentrations $(\leq 2.50 \mathrm{mIU} / \mathrm{L})$ were characterised by the lowest (favourable) waist-to-hip ratio (WHR), lowest concentration levels of total cholesterol, LDL cholesterol, triglycerides, and significantly lower fasting glucose and insulin lev- 
els, as well as a lower oral glucose tolerance test results than patients with TSH concentrations in the upper half of the reference range and with TSH $>4.50 \mathrm{mIU} / \mathrm{L}$. Similar observations were made by German researchers, who examined 1333 people with normal TSH concentrations and demonstrated an increased risk of developing metabolic syndrome in people with TSH concentrations in the upper half of the reference range, compared to patients with TSH concentrations $<2.50 \mathrm{mIU} / \mathrm{L}$, which was indicated by a higher waist-to-hip ratio (WHR) and higher triglyceride concentration [21].

Similar conclusions were also drawn by Souza et al., who demonstrated in a group of 199 obese or overweight teenagers that TSH concentration was positively correlated with the HOMA insulin resistance index, total cholesterol concentration, and triglyceride concentration [22].

Therefore, a TSH concentration in the lower half of the reference range for the general population $(<$ $2.50 \mathrm{mIU} / \mathrm{L}$ ) seems to have a protective impact on the organism by reducing cardiovascular risk [20, 23, 24].

The arising questions are whether pharmacology is the only way to lower the TSH level and at what stage starting the treatment with L-thyroxine seems to be inevitable.

According to Wolters et al. as well as Reinehr et al., substantial weight loss can be associated with lowering TSH levels in obese children and adolescents [25, 26]. However, most scientists agree that the treatment with L-thyroxine seems to be advisable when TSH level is above $10 \mathrm{mIU} / \mathrm{L}$ [27], which we also did in the case of three patients in our study.

It is also worth mentioning the article of Witkowska-Sędek et al., in which the authors claim that the treatment of subclinical hypothyroiditis and in such a way, lowering the level of TSH, can make it harder for obese teenagers to maintain reduced body weight [28].

Diagnostic criteria of metabolic syndrome in teenagers between 10-16 years old are still being discussed, and it is hard to find valuable data about the incidence of metabolic syndrome in this age group [29]. In our study, metabolic syndrome was diagnosed in $7.5 \%$ of all analysed patients but in $20 \%$ of teenagers with BMI above $30 \mathrm{~kg} / \mathrm{m}^{2}$.

The aim of PoZdro! - National Program for the Prevention of Diabetes and Civilisation-related Diseases - is to raise public awareness of healthy lifestyle expressed through a healthy, balanced diet and regular physical exercise, which should result in a reduction of body weight in overweight or obese teenagers taking part in the two-year program.

We hope that re-testing thyroid hormonal parameters after the completion of this study, which should result in a reduction of our patients' body mass, will provide further interesting conclusions regarding the association of TSH and fT4 concentrations and the risk of developing metabolic syndrome in children and adolescents.

\section{Conclusions}

TSH concentration in the upper half of the current reference range $(>2.50 \mathrm{mIU} / \mathrm{L})$ is associated with an increased risk of lipid and carbohydrate metabolism disorders and therefore increased chances of developing metabolic syndrome. It seems advisable to regularly monitor thyroid function in overweight and obese paediatric patients.

\section{Authors disclosure dtatement}

No competing financial interests exist. MB, KS, MR, TA, LC, PS, and MM are members of PoZdro! Program Scientific Board.

\section{References}

1. Güngör NK. Overweight and obesity in children and adolescents. J Clin Res Pediatr Endocrinol. 2014; 6(3): 129-143, doi: 10.4274/Jcrpe.1471, indexed in Pubmed: 25241606.

2. Kowal M, Woronkowicz A, Kryst $€$, et al. Sex differences in prevalence of overweight and obesity, and in extent of overweight index, in children and adolescents (3-18 years) from Kraków, Poland in 1983, 2000 and 2010. Public Health Nutr. 2016; 19(6): 1035-1046, doi: 10.1017/S1368980015002281, indexed in Pubmed: 26239563.

3. Kułaga Z, Gurzkowska B, Grajda A, et al. The prevalence of overweight and obesity among Polish pre-school-aged children. Dev Period Med. 2016; 20(2): 143-149, indexed in Pubmed: 27442700.

4. Wolnicka K, Jarosz M, Jaczewska-Schuetz J, et al. Differences in the prevalence of overweight, obesity and underweight among children from primary schools in rural and urban areas. Ann Agric Environ Med. 2016; 23(2): 341-344, doi: 10.5604/12321966.1203902, indexed in Pubmed: 27294644.

5. Rumińska M, Witkowska-Sẹdek E, Majcher A, et al. Thyroid Function in Obese Children and Adolescents and Its Association with Anthropometric and Metabolic Parameters. Adv Exp Med Biol. 2016; 912: 33-41, doi: 10.1007/5584 2016 232, indexed in Pubmed: 27068926.

6. Steinberger J, Daniels S, Eckel R, et al. Progress and Challenges in Metabolic Syndrome in Children and Adolescents. Circulation. 2009; 119(4): 628-647, doi: 10.1161/circulationaha.108.191394.

7. Firek-Pędras M, Małecka-Tendera E, Klimek K. Wpływ rozmieszczenia tkanki tłuszczowej na zaburzenia metaboliczne u dzieci i młodzieży $z$ otyłością prostą. [The influence of fat tissue collocation on metabolic disorders in children and teenagers with simple obesity]. Endok. Diabet Chor. Przem. Materii Wieku Rozwoj. 2006; 12: 19-24.

8. Sanyal D, Raychaudhuri M. Hypothyroidism and obesity: An intriguing link. Indian J Endocrinol Metab. 2016; 20(4): 554-557, doi: 10.4103/2230-8210.183454, indexed in Pubmed: 27366725.

9. Sorof JM, Lai D, Turner J, et al. Overweight, ethnicity, and the prevalence of hypertension in school-aged children. Pediatrics. 2004; 113(3 Pt 1): 475-482, indexed in Pubmed: 14993537.

10. Titmuss AT, Srinivasan S. Metabolic syndrome in children and adolescents: Old concepts in a young population. J Paediatr Child Health. 2016; 52(10): 928-934, doi: 10.1111/jpc.13190, indexed in Pubmed: 27301065.

11. Januszek-Trzciakowska A, Malecka-Tendera E. Subkliniczna niedoczynność tarczycy u otyłych dzieci [Subclinical hypothyroidism in obese children]. Postepy Hig Med Dosw (Online). 2013; 67: 770-774, doi: 10.5604/17322693.1061415, indexed in Pubmed: 24018443.

12. Kulaga $Z$, Litwin M, Tkaczyk M, et al. The height-, weight-, and BMI-for-age of Polish school-aged children and adolescents relative to international and local growth references. BMC Public Health. 2010; 10: 109, doi: 10.1186/1471-2458-10-109, indexed in Pubmed: 20199693.

13. Kułaga Z, Litwin M, Tkaczyk M, et al. Polish 2010 growth references for school-aged children and adolescents. Eur J Pediatr. 2011; 170(5): 599-609, doi: 10.1007/s00431-010-1329-x, indexed in Pubmed: 20972688. 
14. Zimmet P, Alberti KG, Kaufman F, et al. IDF Consensus Group. The metabolic syndrome in children and adolescents - an IDF consensus report. Pediatr Diabetes. 2007; 8(5): 299-306, doi: 10.1111/j.1399-5448.20 07.00271.x, indexed in Pubmed: 17850473.

15. Knudsen N, Laurberg P, Rasmussen LB, et al. Small differences in thyroid function may be important for body mass index and the occurrence of obesity in the population. J Clin Endocrinol Metab. 2005; 90(7): 4019-4024, doi: 10.1210/jc.2004-2225, indexed in Pubmed: 15870128.

16. Ruhla S, Weickert MO, Arafat AM, et al. A high normal TSH is associated with the metabolic syndrome. Clin Endocrinol (Oxf). 2010; 72(5): 696-701, doi: 10.1111/j.1365-2265.2009.03698.x, indexed in Pubmed: 20447068

17. Tiller D, Ittermann T, Greiser KH, et al. Association of Serum Thyrotropin with Anthropometric Markers of Obesity in the General Population. Thyroid. 2016; 26(9): 1205-1214, doi: 10.1089/thy.2015.0410, indexed in Pubmed: 27393002.

18. Sert A, Pirgon O, Aypar E, et al. Subclinical Hypothyroidism as a Risk Factor for the Development of Cardiovascular Disease in Obese Adolescents With Nonalcoholic Fatty Liver Disease. Pediatric Cardiology. 2013; 34(5): 1166-1174, doi: 10.1007/s00246-013-0638-z.

19. Asvold BO, Vatten LJ, Nilsen TIL, et al. The association between TSH within the reference range and serum lipid concentrations in a population-based study. The HUNT Study. Eur J Endocrinol. 2007; 156(2): 181-186, doi: 10.1530/eje.1.02333, indexed in Pubmed: 17287407.

20. Radetti G, Grugni G, Lupi F, et al. The relationship between hyperthyrotropinemia and metabolic and cardiovascular risk factors in a large group of overweight and obese children and adolescents. J Endocrinol Invest. 2017; 40(12): 1311-1319, doi: 10.1007/s40618-017-0705-z, indexed in Pubmed: 28585021.

21. Reinehr T. Thyroid function in the nutritionally obese child and adolescent. Curr Opin Pediatr. 2011; 23(4): 415-420, doi: 10.1097/MOP.0b013e328344c393, indexed in Pubmed: 21430532.
22. Souza L, Guedes E, Teixeira P, et al. Serum TSH levels are associated with cardiovascular risk factors in overweight and obese adolescents. Jornal de Pediatria. 2016; 92(5): 532-538, doi: 10.1016/j.jped.2016.01.011.

23. García-García E, Vázquez-López MA, García-Fuentes E, et al. Thyroid Function and Thyroid Autoimmunity in Relation to Weight Status and Cardiovascular Risk Factors in Children and Adolescents: A Population-Based Study. J Clin Res Pediatr Endocrinol. 2016; 8(2): 157-162, doi: 10.4274/jcrpe.2687, indexed in Pubmed: 26761948.

24. Brufani C, Manco M, Nobili V, et al. Thyroid function tests in obese prepubertal children: correlations with insulin sensitivity and body fat distribution. Horm Res Paediatr. 2012; 78(2): 100-105, doi: 10.1159/000341363, indexed in Pubmed: 22846232.

25. Wolters B, Lass N, Reinehr T. TSH and free triiodothyronine concentrations are associated with weight loss in a lifestyle intervention and weight regain afterwards in obese children. Eur J Endocrinol. 2013; 168(3): 323-329, doi: 10.1530/EJE-12-0981, indexed in Pubmed: 23211576.

26. Reinehr T, de Sousa G, Andler W. Hyperthyrotropinemia in obese children is reversible after weight loss and is not related to lipids. J Clin Endocrinol Metab. 2006; 91(8): 3088-3091, doi: 10.1210/jc.2006-0095, indexed in Pubmed: 16684827.

27. Pearce SHS, Brabant G, Duntas LH, et al. 2013 ETA Guideline: Management of Subclinical Hypothyroidism. Eur Thyroid J. 2013; 2(4): 215-228, doi: 10.1159/000356507, indexed in Pubmed: 24783053.

28. Witkowska-Sędek E, Kucharska A, Rumińska M, et al. Thyroid dysfunction in obese and overweight children. Endokrynol Pol. 2017; 68(1): 54-60, doi: 10.5603/EP.2017.0007, indexed in Pubmed: 28255980.

29. Oliveira RG, Guedes DP. Performance of anthropometric indicators as predictors of metabolic syndrome in Brazilian adolescents. BMC Pediatr. 2018; 18(1): 33, doi: 10.1186/s12887-018-1030-1, indexed in Pubmed: 29415673 